\title{
The Patient Focused Outcomes of Neuroma Excision at a Mean Follow-up of 8 Years and 10 Months
}

Andrew Coutts ( $\square$ andrewcoutts@msn.com )

Derbyshire Community Health Services NHS Foundation Trust

Tim Kilmartin

Derbyshire Community Health Services NHS Foundation Trust

\section{Research}

Keywords: neurectomy, Morton's neuroma, foot, ultrasound, histopathology

Posted Date: September 8th, 2020

DOI: https://doi.org/10.21203/rs.3.rs-73573/v1

License: 우 (i) This work is licensed under a Creative Commons Attribution 4.0 International License. Read Full License 


\section{Abstract}

Background - While the majority of patients do well following neuroma excision, good outcomes are far from universal. Hence we always provide a course of non-surgical treatment prior to surgery - footwear advice, orthotics, patient education and up to 3 corticosteroid injections. Furthermore, we wanted to understand and quantify the risks and complication to allow us to be able to provide this information to patients during informed consent.

Methods - Between 2000 and 2012 neuroma excision from the $2^{\text {nd }}$ intermetatarsal or $3^{\text {rd }}$ intermetatarsal space was carried out consecutively on 42 cases ( 36 patients), for the treatment of IM neuroma pain. Three patients from the cohort died prior to follow-up and 6 cases failed to attend for review.

The outcomes of surgery were measured in a service review using a visual analogue pain scale, the Manchester Oxford Foot Questionnaire, clinical examination of the foot and consultation with the patient where any adverse issues were recorded.

The mean follow-up period was 8-years and 10-months (range 61-194 months). At the time of surgery, the mean age of the patients was 54-years of age (range 25-74 years) and at follow-up the mean age was 63-years of age (range 31-85 years).

Results - Twenty four cases (73\%) reported they were completely satisfied with the results of their surgery, 8 cases (24\%) were satisfied with reservations and 1 case (3\%) reported they were dissatisfied. All cases agreed they would be happy to undergo surgery under similar circumstance again if required, i.e. under local anaesthesia on a day case basis. 2 cases (6\%) reported recurrence of symptoms and required revision surgery which was performed in one case at 9 years and in the other at 11-years. After further excision of nerve tissue, their symptoms resolved.

Conclusion - Neuroma excision is a reasonably safe and effective treatment for neuroma pain when non-surgical treatments fail to resolve symptoms. Our approach requires meticulous clinical examination and history taking, up to three cortisone injections and then ultrasound examination before the patient is listed for surgery. In this way we hope to minimise the risk of incorrect diagnosis and continued pain post excision due to the presence of undiagnosed capsulitis.

\section{Introduction}

IM neuroma is a benign fibrotic thickening of a plantar IM nerve often found in the 2nd and 3rd IM and is believed to be a common cause of forefoot pain [1]. Within the literature it is most often referred to as a Morton's neuroma when it is found within the 3rd IM space as it was originally described, however some articles have now adopted the term 'Morton's neuroma' to also describe a neuroma of the 2nd IM space.

Orthotic insoles and cortisone injections may be used as a non-surgical treatment though there is little evidence to support their use [2]. Excision of the IM nerve is the most commonly performed surgical intervention though transposition of the nerve and neurolysis has also been described [3]. Satisfactory outcomes of neuroma excision rarely exceed $80 \%$ [4] and for that reason non-surgical treatment is strongly indicated prior to surgical excision. In providing a pathway for conservative treatment which commenced with footwear advice and orthotic treatment, followed by cortisone injection therapy, Bennett et al (1995) [4] found that only $21 \%$ of 115 patients required surgical excision of the nerve. They also made the point that although cortisone injections may only give short term relief, a positive injection response is an essential prerequisite prior to recommending surgery. In advocating this approach it was recognised that one reason for neuroma surgery failure is misdiagnosis of neuroma when other causes of forefoot pain, principally synovitis of the MTP joints is in fact the cause.

Adverse events are common following neuroma surgery and include numbness of the toes and continued or recurrent pain. In a review of 39 patients Beskin et al (1988) [5] noted two types of painful outcomes, those that remain symptomatic after neurectomy and those that pain recurs after a period of relative comfort. The latter group which accounted for one third of adverse outcomes were thought to be related to the development of stump neuroma. This has implications for neuroma sufferers undergoing surgery as they need to know if their neuroma pain could recur and over what time period.

The following study presents a service review with a mean average of almost nine years follow-up of 2nd and 3rd IM space neuroma excision in a series of 33 cases who all received between 2 and 3 corticosteroid injections prior to undergoing surgery. Ultrasound examination by a specialist musculo-skeletal Consultant Radiologist was also performed prior to surgery to confirm the presence of neuroma. Using this approach we believed that the neuroma diagnosis was more reliable and in turn we expected this would improve outcomes.

A long-term follow-up was necessary in order to establish whether recurrence of neuroma pain due to stump neuroma occurred. In all cases neuroma excision was performed through a dorsal incision. The outcomes of surgery were measured using a visual analogue pain scale, the MOxFQ [6], clinical examination of the foot and consultation with the patient where any adverse issues were recorded. Other reported outcomes include a correlation of the size of the neuroma measured on ultrasound prior to surgery and the size of the neuroma measured on histopathology after surgical excision and the size of the neuroma was also correlated with the pre-operative visual analogue pain score. Ultimately the aim of this study was to establish whether our approach of corticosteroid injection therapy and confirmation of the interdigital neuroma diagnosis by ultrasound examination prior to surgical excision through a dorsal incision can be recommended as a pathway with satisfactory long-term outcomes.

\section{Material And Methods}

Between 2000 and 2012 neuroma excision from the $2^{\text {nd }}$ or $3^{\text {rd }} I M$ space was carried out consecutively on 42 cases (36 patients), for the treatment of IM neuroma pain. Three patients from the cohort died prior to follow-up. All patients were referred to a hospital based National Health Service Podiatric Surgery unit by their General Practitioner or Allied Health Professional and underwent surgery when conservative measures including orthoses and no less than 2 but 
no more than 3 cortisone injections had proved ineffective. Diagnosis was based on history taking and physical examination. A positive finding was pain on the bilateral squeeze test, pain on dorsal to plantar pressure of the IM space and of the IM sulci (fig1).

Diagnosis was further supported by positive ultrasound findings established on examination by a Consultant Radiologist. In 2017 the remaining 39 cases (33 patients) were contacted and invited to once more attend the unit for follow-up and review. Six cases failed to attend for review. Of the remaining 33 cases ( 27 patients) reviewed by the primary author, 26 patients were female. Six female patients had undergone bilateral procedures at separate occasions. Ten cases were neuroma excision from the $2^{\text {nd }} \mathrm{IM}$ space and 23 cases were neuroma excision from the $3^{\text {rd }} \mathrm{IM}$ space. The mean follow-up period was 8 years and 10 months (range 61-194 months). At the time of surgery, the mean age of the patients was 54 years of age (range 25-74 years) and at follow-up the mean age was 63 years of age (range $31-85$ years).

In all cases the procedure was performed by the second author and the review performed by the primary author. The patients were questioned using a standard format to assess their pain levels, footwear fitting problems, activity levels, cosmesis, numbness, any complications and any other issues. Patient satisfaction levels were recorded via questioning and the MOxFQ. The MOxFQ is a patient reporting outcome measurement developed and validated for the use in studies assessing outcomes following foot and ankle surgery. Originally the MOxFQ was developed as an outcome measurement for hallux valgus surgery, but was amended and validated for the use among patients with a variety of foot and ankle problems. It has been reported to show good content, test and retest reliability. It has been validated for use as a post-operative outcome measure [6].

The MOxFQ consists of 16 questions looking at the three outcomes measured by this patient reported outcome measurement which are pain, walking/standing ability and social interaction. These 3 outcomes are thought to assess how foot problems impair on health-related quality of life. The response options to the MOxFQ consist of a 5 point Likert scale ranging from no limitation to maximum limitation. This provides a score from $0-100$ with 100 equalling most severe; the lower the score the less severe the problem. This outcome measure has been used successfully in other clinical cohort studies [7, 8].

\section{Operative technique}

In all cases the procedure was performed as a day case operation under ankle block anaesthesia. An ankle tourniquet was applied and a dorsal skin incision was extended from the web space of either the $2^{\text {nd }}$ or $3^{\text {rd }}$ toes proximally for up to 4 centimetres into the IM space. Vessels were clamped and cauterised to avoid any bleeding into the IM space. Then blunt dissection was carried out down to the level of the IM space and the neuroma identified (fig 2) and the transverse ligament released.

Using tenotomy scissors the nerve was divided distally at the base of the toes and then dissected proximally between 2-3cms proximal to the metatarsal head. A distal tension was placed on the nerve and then it was transected and the stump pushed proximally into the fibro-osseous tunnel.

Deep closure was carried out using 2-0 Vicryl and the skin closed with subcuticular 4-0 Monocryl sutures.

All specimens were sent for histopathological examination.

The foot was bandaged and placed in a stiff soled surgical shoe for 2 weeks and all cases were encouraged to heel walk for 5 minutes in every hour. All dressings were removed at 2 weeks' post-operative and then all cases were asked to return to lace-up trainer/sport shoes and then gradually return to normal activities. All cases were again reviewed at 6-months post-operatively and then discharged.

\section{Results}

At final review, pain and activity levels were assessed using standardised questions for all cases. Patient satisfaction with their surgical outcome was recorded qualitatively as completely satisfied, satisfied with reservations or dissatisfied. Reasons for reservations and dissatisfaction were recorded. Cosmetic concerns, footwear fitting difficulties and post-operative complications were also recorded.

Twenty four cases (73\%) reported they were completely satisfied with the results of their surgery, 8 cases (24\%) were satisfied with reservations and 1 case (3\%) reported they were dissatisfied (Table 1). All cases agreed they would be happy to undergo surgery under similar circumstance again if required, i.e. under local anaesthesia on a day case basis.

The cases that were satisfied with reservation, complained of symptoms only improved by $60 \%$ in one case, continued footwear restrictions in 5 cases and in 2 further cases who were satisfied with reservations had undergone neuroma excision from the 3rd IM space but required revision surgery because of continued pain which was performed in one case at 9 years and in the other at 11 years. After further excision of nerve tissue, their symptoms resolved. 
Table 1

Patient satisfaction and reasons for reservations and dissatisfaction

\begin{tabular}{|llll|}
\hline Number of cases & Satisfied & Satisfied with reservations & Dissatisfied \\
\hline 24 cases $(73 \%)$ & $\mathrm{X}$ & & \\
\hline 8 cases $(24 \%)$ & 5 footwear restrictions & \\
& 2 revision surgery & \\
& & 1 symptoms only improved by $60 \%$ & \\
& & 1 No improvement of symptoms \\
\hline
\end{tabular}

The one dissatisfied case reported their symptoms were no better but at review this patient presented with 2nd MTP joint capsulitis which was treated successfully with orthotics, footwear advice and cortisone therapy. However, prior to undergoing neuroma surgery clinical diagnosis had been made and diagnostic ultrasound examination identified a $6 \mathrm{~mm}$ neuroma. Subsequent histopathology confirmed a neuroma $15 \mathrm{~mm}$ wide had been excised. A possible cause of continued pain was capsulitis due to reduced plantar fat pad following the neuroma excision as clearly the IM nerve is part of the plantar fat pad and removal of the neuroma can leave a reduced plantar fat pad.

Twenty six of the 33 cases in the cohort (26/33) recorded a visual analogue score prior to surgery. The size of the neuroma on pre-operative ultrasound examination and the size on post-operative histopathology was compared in order to test if there was any correlation between the size of the neuroma and pre-operative pain levels. A highly statistically significant correlation value of $0.74 p>0.001$ was established (Table 4).

Three outcomes were measured by the MOxFQ; pain, walking/standing ability and social interaction, with the lower the score, the greater the improvement in the patients symptoms. The mean average scores for the 3 outcomes were pain 9.5/100, walking/standing 7.5/100 and social interaction 5/100. Additionally, $67 \%$ of patients $(14 / 21)$ reported a score of 0 for pain and walking/standing and $76 \%(16 / 21)$ of patients reported a score of 0 for social interaction outcomes.

Patients were asked if their pain was better than pre-operative with 32/33 (97\%) reporting they were improved; however the one case with continued capsulitis pain considered they were no better.

Cosmetically, $100 \%$ of patients were happy with the appearance of their foot and none had any concerns about the post-operative scar.

Beech et al 2000 reported a loss of sensation to the adjacent toes has been found to effect up to $59 \%$ of patients following neuroma excision [9]. All the patients in this study were sensate to a $10 \mathrm{~g}$ monofilament plantar and dorsal to the area of surgery and adjacent toes. However, $16 / 33$ (48\%) patients reported a perception of altered sensation or 'numbness' in the adjacent toes. Altered sensation in the toes was recorded in 5/10 (50\%) of 2nd IM space neuroma excisions and 11/23 (48\%) of 3rd IM space neuroma excisions, however no case perceived this to be a problem.

All patients reported no activity restrictions at long-term follow-up whilst $100 \%$ of patients had reported footwear restrictions prior to surgery, only $1 / 33$ ( $3 \%$ ) reported footwear restrictions at long-term follow-up which was the patient previously described as being confined to a trainer/sport shoe.

Table 2

Pre-operative size on ultrasound compared to satisfaction rates $\mathrm{N}=23$

\begin{tabular}{|c|c|c|c|c|}
\hline Size of neuroma on ultrasound & Number of cases & Totally satisfied & Satisfied with reservation & Dissatisfied \\
\hline $4 \mathrm{~mm}$ & 1 & $1(100 \%)$ & & \\
\hline $5 \mathrm{~mm}$ & 4 & $2(50 \%)$ & $2(50 \%)$ & \\
\hline $6 \mathrm{~mm}$ & 3 & $3(100 \%)$ & & \\
\hline $7 \mathrm{~mm}$ & 5 & $4(80 \%)$ & $1(20 \%)$ & \\
\hline $8 \mathrm{~mm}$ & 5 & $5(100 \%)$ & & \\
\hline $9 \mathrm{~mm}$ & 2 & $1(50 \%)$ & $1(50 \%)$ & \\
\hline $10 \mathrm{~mm}$ & 3 & $1(33 \%)$ & $2(66 \%$ & \\
\hline
\end{tabular}


Table 3

- Pre-operative VAS pain score compared to patient satisfaction compared $\mathrm{N}=24$

\begin{tabular}{|llll|}
\hline VAS pain score pre-operatively & Totally satisfied & Satisfied with reservations & Dissatisfied \\
\hline $4(n=1)$ & & 1 & 1 \\
\hline $5(n=3)$ & 2 & & \\
$6(n=10)$ & 9 & 1 & \\
$7(n=2)$ & 1 & 1 & \\
$8(n=3)$ & 3 & & \\
$9(n=4)$ & 2 & 2 \\
\hline $10(n=1)$ & & 1 & \\
\hline
\end{tabular}

Table 4

- Correlation between neuroma size as measured on ultrasound and pre op VAS score. Pearson correlation $r=0.74, p<0.001$

\begin{tabular}{|llll|}
\hline Size of neuroma on ultrasound & Number of cases & Range of VAS & Mean of VAS (0-10) \\
\hline $4 \mathrm{~mm}$ & 1 & 5 & 5 \\
\hline $5 \mathrm{~mm}$ & 4 & $5-7$ & 6 \\
\hline $6 \mathrm{~mm}$ & 3 & 6 & 6 \\
\hline $7 \mathrm{~mm}$ & 5 & $4-6$ & 5.6 \\
\hline $8 \mathrm{~mm}$ & 5 & $6-9$ & 7.6 \\
\hline $9 \mathrm{~mm}$ & 2 & $8-9$ & 8.5 \\
\hline $10 \mathrm{~mm}$ & 3 & $9-10$ & 9.3 \\
\hline
\end{tabular}

Table 5

Size of neuroma on ultrasound pre-operatively compared to post-operative histopathology report $N=21$. Pearson correlation $r=0.43, p<0.05$.

\begin{tabular}{|lllll|}
\hline $\begin{array}{l}\text { Size of neuroma on } \\
\text { ultrasound }\end{array}$ & $\begin{array}{l}\text { Number of } \\
\text { cases }\end{array}$ & $\begin{array}{l}\text { Mean size of neuroma on } \\
\text { histopathology }\end{array}$ & $\begin{array}{l}\text { Range of size of neuroma on } \\
\text { histopatholgy }\end{array}$ & $\begin{array}{l}\text { Difference ultrasound to } \\
\text { histopathology }\end{array}$ \\
\hline $4 \mathrm{~mm}$ & 1 & $4 \mathrm{~mm}$ & $4 \mathrm{~mm}$ & $0 \mathrm{~mm}$ \\
\hline $5 \mathrm{~mm}$ & 4 & $7.5 \mathrm{~mm}$ & $6-9 \mathrm{~mm}$ & $2.5 \mathrm{~mm}$ \\
\hline $6 \mathrm{~mm}$ & 2 & $8 \mathrm{~mm}$ & $8 \mathrm{~mm}$ & $1.5 \mathrm{~mm}$ \\
\hline $7 \mathrm{~mm}$ & 4 & $8.5 \mathrm{~mm}$ & $6-10 \mathrm{~mm}$ & $2 \mathrm{~mm}$ \\
\hline $8 \mathrm{~mm}$ & 5 & $10 \mathrm{~mm}$ & $5-13 \mathrm{~mm}$ & $0 \mathrm{~mm}$ \\
\hline $9 \mathrm{~mm}$ & 2 & $9 \mathrm{~mm}$ & $8-10 \mathrm{~mm}$ & $-1 \mathrm{~mm}$ \\
\hline $10 \mathrm{~mm}$ & 3 & $9 \mathrm{~mm}$ & $7-11$ & \\
\hline
\end{tabular}

\section{Discussion}

The outcomes of neuroma excision have been investigated on numerous occasions [2]. While the majority of patients do well, good outcomes are far from universal. For this reason we always provide a course of non-surgical treatment prior to surgery including - footwear advice, orthotics, patient education and up to 3 corticosteroid injections in a 12 month period. The effectiveness of this non-surgical treatment and cortisone injections in the management of neuroma pain is however only partially supported by the literature. Greenfield et al 1984 reported that cortisone injections provided complete pain relief in $30 \%$ and partial pain relief in $50 \%$ of patients. $95 \%$ of the patients reporting complete pain relief remained asymptomatic at 2 year follow-up [10]. Bennett et al 1995 noted that $85 \%$ of 115 patients found that they had improvement from non-surgical treatment and just $21 \%$ required surgical excision [4]. However, in a systematic review of non-surgical interventions Matthews et al 2019 found only limited evidence for non-surgical treatment though it was still recommended that non-surgical treatment should always be attempted prior to surgery $[11,12,13,14]$.

We have however found that providing a course of conservative treatment allows us to be more certain of the diagnosis as at each conservative treatment review we ask the patient to describe their symptoms again and then perform a clinical examination to determine the location of their pain as well as their response to palpation of the IM spaces and lesser MTP joint capsules. Additionally Pace et al 2010 reported non-operative treatments only offered short-term relief in their experience, but more importantly they found cortisone injections more useful as a diagnostic rather than therapeutic measure [15]. We believe that the poorest surgical outcomes are due to misdiagnosis of neuroma when in fact the patient was suffering from lesser MTP joint capsulitis. It is our observation that pain in the region of the $2 \mathrm{nd} / 3 \mathrm{rd} \mathrm{IM}$ space carries the greatest risk of misdiagnosis as the 2 nd MTP joint is commonly the site of capsulitis. 
Detailed discussion of the patient's symptoms is crucial. Patients with capsulitis pain will describe a feeling of walking on a marble that is exacerbated by walking in stiff or thin soled shoes on hard pavement or concrete surfaces. Neuroma pain is less precise. It is unpredictable in onset, some shoes will feel comfortable one day but not the next, though narrow shoes that constrict the width of the foot seem to reliably exacerbate symptoms. The patient will often complain of paraesthesia in the area and numbness though on further questioning this is less a total absence of sensation and more an altered sensation. A more reliable neuroma symptom is intense pain that develops after a period of activity and is relieved by removing shoes to massage the affected intermetatarsal space.

Combined symptoms of neuroma and capsulitis pain can also present. In these cases we inject the involved IM space with $5 \mathrm{mls}$ of $0.5 \%$ Levobupivacaine and ask the patient to exercise on the foot and report how their symptoms were affected while the area was anaesthetised. Unfortunately the response is not always clear cut and in these circumstances we inject $40 \mathrm{mg}$ of depomedrone corticosteroid into the IM space and review the response once again. If there is no improvement we then consider a course of cortisone injections to the adjacent MTP joint capsules.

Ultrasound examination of the foot for IM neuroma is operator dependant and although findings are often helpful, they are for us, not as important as clinical history. Much work remains to be done on the reliability of ultrasound neuroma diagnosis. In particular the significance of lesion size has been alluded to in the past with studies correlating the size of the neuroma with post-operative outcomes. As a result of this study we consider a lesion less than 6 mm in diameter to be insignificant. This is similar to Volpe et al 1998, who suggested a higher incidence of false positive diagnosis when ultrasound determined a neuroma less than $6 \mathrm{~mm}$ in diameter. Redd et al 1989 and Zanetti et al 1997 observed that neuromas measuring less than $6 \mathrm{~mm}$ on ultrasound and MRI could not be correlated to clinical findings $[16,17,18]$.

We attempted to determine if neuroma surgery success could be predicted by considering the following four issues;

1. Is the surgical outcome better when the neuroma is larger when measured on pre-operative ultrasound examination? Could it be that the larger the neuroma the more certain the diagnosis and the less likely the patient is suffering from another cause of forefoot pain? Unfortunately the number of the cases in this series was not sufficient to determine any statistically significant relationship between the size of the neuroma lesion and the subsequent surgical outcome (Table 2).

2. Does the pre-operative pain level relate to the outcome of surgery based on post-operative patient satisfaction? No obvious correlation was found in this series of cases (Table 3).

3. Does the level of pre-operative pain relate to the size of the neuroma measured on pre-operative ultrasound? When the size of the neuroma measured on ultrasound was correlated with the pre-operative visual analogue scores there was a strong correlation between size of the neuroma and the level of symptoms with neuromas greater than $7 \mathrm{~mm}$ in diameter causing high levels of pain. In line with other studies surgical excision of neuromas measuring less than $6 \mathrm{~mm}$ on pre-operative ultrasound is likely to have an unpredictable outcome [16] (Table 4).

4. Does the size of the neuroma on pre-operative ultrasound reflect the size of the neuroma measured histopathologically after excision? A weak statistically significant correlation was found between ultrasound measurement and histopathological measurement of the neuroma (Table 5). 
Table 6

a comparison of studies looking at the outcomes of neuroma surgery.

\begin{tabular}{|c|c|c|c|c|c|}
\hline Year & Study & Cohort & $\begin{array}{l}\text { Mean follow- } \\
\text { up (months) }\end{array}$ & Result & Complications \\
\hline \multirow[t]{7}{*}{2019} & \multirow[t]{7}{*}{ Coutts and Kilmartin } & \multirow[t]{7}{*}{33} & \multirow[t]{7}{*}{106} & $73 \%$ totally satisfied & $48 \%$ numbness \\
\hline & & & & $24 \%$ satisfied with reservations & \multirow[t]{6}{*}{$6 \%$ recurrence of symptoms } \\
\hline & & & & $3 \%$ dissatisfied & \\
\hline & & & & $97 \%$ better from surgery & \\
\hline & & & & $100 \%$ happy with appearance of foot & \\
\hline & & & & Footwear fitting improved & \\
\hline & & & & $0 \%$ activity restrictions & \\
\hline \multirow[t]{4}{*}{2016} & \multirow[t]{4}{*}{ Flanagan and Reilly [19] } & \multirow[t]{4}{*}{48} & \multirow[t]{4}{*}{6} & \multirow[t]{4}{*}{$95 \%$ better or much better } & $2.4 \%$ recurrence of symptoms \\
\hline & & & & & $2.4 \%$ no improvement \\
\hline & & & & & $4.7 \%$ scar hypertrophy (plantar incision) \\
\hline & & & & & Numbness not reported on \\
\hline \multirow[t]{3}{*}{2011} & \multirow{3}{*}{$\begin{array}{l}\text { Lee, Kim, Young, Park, Kim, } \\
\text { Jegal }[20]\end{array}$} & \multirow[t]{3}{*}{20} & \multirow[t]{3}{*}{126} & \multirow{3}{*}{$\begin{array}{l}31 \% \text { completely satisfied, } \\
69 \% \text { satisfied with minor and major } \\
\text { reservations. }\end{array}$} & $85 \%$ numbness \\
\hline & & & & & $33 \%$ footwear restriction \\
\hline & & & & & $18 \%$ activity restriction \\
\hline \multirow[t]{2}{*}{2010} & \multirow[t]{2}{*}{ Pace, Scammell, Dhar [15] } & \multirow[t]{2}{*}{82} & \multirow[t]{2}{*}{54} & $82 \%$ excellent or good results & $8 \%$ had no improvement \\
\hline & & & & $\begin{array}{l}10 \% \text { fair results with restriction of } \\
\text { activities or pain }\end{array}$ & $71 \%$ had footwear restrictions \\
\hline \multirow[t]{3}{*}{2008} & \multirow[t]{3}{*}{ Womack et al [21] } & \multirow[t]{3}{*}{120} & \multirow[t]{3}{*}{66} & $50 \%$ good results, & $78 \%$ numbness \\
\hline & & & & $10 \%$ fair results, & \multirow{2}{*}{$\begin{array}{l}\text { Revision procedure excluded and number } \\
\text { not noted. }\end{array}$} \\
\hline & & & & $\begin{array}{l}40 \% \text { poor results (based on non- } \\
\text { validated clinical scoring system) }\end{array}$ & \\
\hline \multirow[t]{8}{*}{2004} & \multirow{8}{*}{$\begin{array}{l}\text { Giannini, Bacchini, } \\
\text { Ceccarerelli, Vannini [22] }\end{array}$} & \multirow[t]{8}{*}{63} & 47 & $68 \%$ pain free & $38 \%$ numbness \\
\hline & & & & $90 \%$ increase in activity & \\
\hline & & & & Footwear fitting improved & \\
\hline & & & & $50 \%$ excellent results & \\
\hline & & & & $16 \%$ good results & \\
\hline & & & & $20 \%$ fair results & \\
\hline & & & & $3 \%$ poor results & \\
\hline & & & & $\begin{array}{l}\text { (based on non-validated clinical scoring } \\
\text { system) }\end{array}$ & \\
\hline 2004 & Stamatis and Myerson [23] & 49 & 40 & $31 \%$ completely satisfied & $65 \%$ numbness \\
\hline & & & & $26.5 \%$ satisfied with minor reservations & $59 \%$ moderate or severe restriction of \\
\hline & & & & $20 \%$ satisfied with major reservations & $16 \%$ moderat \\
\hline & & & & $22 \%$ dissatisfied & $12 \%$ CRPS (no diagnostic criteria noted) \\
\hline 2001 & Coughlin and & 71 & 70 & $85 \%$ high patient satisfaction & $70 \%$ mild/major footwear restrictions \\
\hline & & & & $65 \%$ pain free & $51 \%$ numbness \\
\hline 2000 & Beech, Rees and Tagoe [9] & 34 & 27 & $47 \%$ completely satisfied, & $59 \%$ numbness \\
\hline & & & & $47 \%$ satisfied with reservations. & $6 \%$ dissatisfied \\
\hline & & & & $91 \%$ better from surgery & \\
\hline 1996 & $\begin{array}{l}\text { Benedetti, Baxter and } \\
\text { Davis [25] }\end{array}$ & 19 & 69 & $53 \%$ complete resolution of pain & $16 \%$ continued significant pain \\
\hline & & & & $31 \%$ minimal residual symptoms & $\begin{array}{l}\text { Some degree of numbness reported in all } \\
\text { patients }\end{array}$ \\
\hline
\end{tabular}




\begin{tabular}{|llllll|}
\hline Year & Study & Cohort & $\begin{array}{l}\text { Mean follow- } \\
\text { up (months) }\end{array}$ & Result & Complications \\
\hline 1995 & Wilson and Kuwada [26] & 59 & 180 & $68 \%$ complete pain relief & $10 \%$ stump neuromas \\
& & & & $\begin{array}{l}25 \% \text { mild pain relief or pain } \\
\text { progressively decreasing }\end{array}$ & $2 \%$ no pain relief \\
\hline 1995 & $\begin{array}{l}\text { Schroven and Geutjens } \\
{[27]}\end{array}$ & 32 & 45 & $60 \%$ pain free & $70 \%$ restriction of footwear \\
& & & & $22 \%$ substantial improvement in pain & $\begin{array}{l}60 \% \text { had to wear adaptive footwear or } \\
\text { orthotics Numbness not reported }\end{array}$ \\
\hline
\end{tabular}

At final review, 73\% of cases reported they were completely satisfied with the results of their surgery. This is relatively high compared with some studies (Table 6) however the studies by Pace et al (2010), Flanagan and Reilly $(2016)$ and Coughlin and Pinsonneault $(2001)[15,19,24)$ all reported higher levels of patient satisfaction, compared to our study.

Pace et al (2010) reported $82 \%$ had excellent or good results and Coughlin and Pinsonneault (2001) reported $85 \%$ high patient satisfaction rate. However, persistent footwear restrictions were reported in $71 \%$ of cases in the series reported by Pace et al (2010) and $70 \%$ of the Coughlin and Pinsonneault study group. In our study this would have reported as satisfied with reservations due to footwear restrictions.

$97 \%$ of our cases reported their pain was better, however, one case (3\%), continued to suffer from pain related to capsulitis of the third MTP joint and we believe this to have been a misdiagnosis $[15,24]$.

Cosmetically, $100 \%$ of patients were happy with the appearance of their foot and no patients had any problems with scarring or the incision and cosmesis was not reported on in any of the papers reviewed. Although many surgeons primary concern for the patients is pain relief, which is echoed by the AOFAS where pain is weighted heavily as 40 points of 100 in total and there is no reporting of cosmesis, we must realise that one of the reasons given for a plantar over dorsal incision is due to the cosmetic appearance of a scar to the dorsum of the foot [28].

Numbness or altered sensation in the adjacent toes was reported in 16/33 (48\%) patients and on comparison of 2nd and 3rd IM neuroma excision, 5/10 (50\%) of 2nd IM neuroma excisions and 11/23 (48\%) of 3rd IM neuroma excisions reported numbness around the site of surgery. However, all patients were sensate to a $10 \mathrm{~g}$ monofilament and none of the cases reported this to be an issue as they'd expected this following surgery as they'd had this explained to them preoperatively.

Significant limitations of this study include the loss of pre-operative data due to the fact that our Trust policy requires that notes be destroyed if the patient has not been seen for seven years. Additionally the validity of the MOxFQ patient reported outcomes were diminished by the absence of pre-operative MOxFQ scores, however the final scores at the follow-up visit were included in order to allow comparison with other studies where the MOxFQ has been applied [7, 29]. We believe the consistency of the outcomes across this case series after such a long period of follow-up, does however allow the findings to be presented with reasonable confidence.

\section{Conclusion}

In this case series, at mean follow-up of 8 years and 10 months, $97 \%$ of patients were better than prior to surgery, $73 \%$ were completely satisfied, $24 \%$ were satisfied with reservations and $3 \%$ were dissatisfied. From the 9 patients who reported reservations and dissatisfaction the reasons were footwear fitting difficulties ( 5 cases), revision surgery at 9 and 11 years ( 2 cases) and potential misdiagnosis ( 1 case) and no improvement (1 case).

This study provides further evidence regarding the outcomes of neuroma excision at long-term follow-up. Neuroma excision is a reasonably safe and effective treatment for neuroma pain when non-surgical treatments fail to resolve symptoms [30, 31, 32, 33, 34]. Our approach requires meticulous clinical examination and history taking, up to three cortisone injections and then ultrasound examination before the patient is listed for surgery. In this way we hope to minimise the risk of incorrect diagnosis and continued pain post excision due to the presence of undiagnosed capsulitis. Additionally, prior to surgery all patients should be advised on the high risk of numbness to the digits and incision site as part of the consent process as $48 \%$ of patients s reported numbness or altered sensation at long-term follow-up.

\section{Abbreviations}

AOFAS - American Orthopaedic Foot and Ankle Scores

IM - Intermetatarsal

MOxFQ - Manchester Oxford Foot Questionnaire

MTP - Metatarsophalangeal

\section{Declarations}

Ethical approval 


\section{Consent for publication}

Dear Andrew Coutts,

Re: The long term patient focussed outcomes of neuroma excision

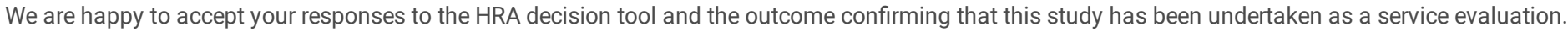

Many thanks and best wishes,

Sarah Creer

Sarah Creer

Research Officer

Research and Innovation Team

Derbyshire Community Health Services NHS FT

sarah.creer@nhs.net

07827246112

\section{Availability of data and materials}

The datasets generated during and/or analysed during the current study are available from the corresponding author on reasonable request.

\section{Competing interests}

The authors declare that they have no competing interests.

\section{Funding}

Service evaluation - No funding was sort.

\section{Authors contribution}

In all cases the procedure was performed by TEK, the calculations

\section{References}

1. NICE. Morton's neuroma: Definition. September 2016. https://cks.nice.org.uk/mortons-neuroma\#!backgroundSub. Accessed 25 June 2020.

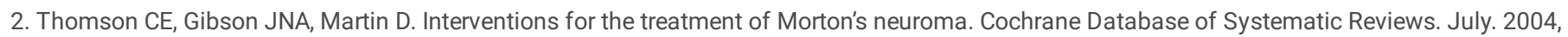
https://www.cochranelibrary.com/cdsr/doi/10.1002/14651858.CD003118.pub2/full. Accessed 25 June 2020.

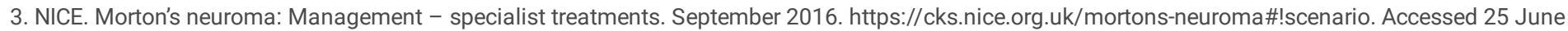
2020 .

4. Bennett GL, Graham CE, Mauldin DM. Morton's interdigital neuroma: a comprehensive treatment protocol. Foot Ankle Int. 1995;16:760-3.

5. Beskin JL, Baxter DE. Recurrent pain following interdigital neurectomy - a plantar approach. Foot Ankle Int. 1988;9:34-9.

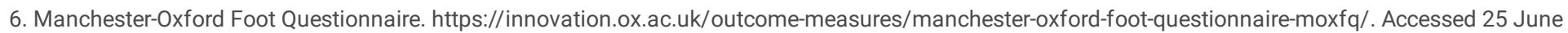
2020.

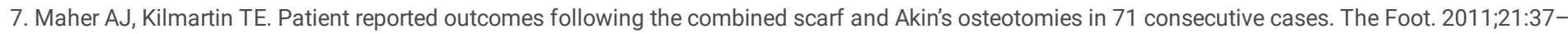
44.

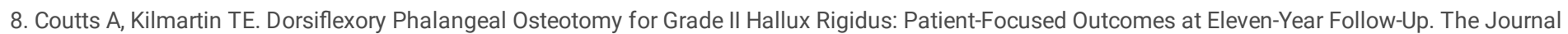
of Foot Ankle Surgery. 2018;58:17-22.

9. Beech I, Rees S, Tagoe. Clinical audit of the surgical management of plantar digital neuroma. The Foot. 2000;10:31-5.

10. Greenfield J, Rea J, Ilfeld FW. Morton's interdigital neuroma - indications for treatment by local injections versus surgery. Clin Orthop Relat Res. 1984;185:142-4.

11. 10.1186/s13047-019-0320-7

Matthews BG, Hurn SE, Harding MP, Henry RA, Ware RS. The effectiveness of non-surgical interventions for common plantar digital compressive neuropathy (Morton's neuroma): a systematic review and meta-analysis. Journal of Foot and Ankle Research, February 2019. 
https://jfootankleres.biomedcentral.com/articles/10.1186/s13047-019-0320-7. Accessed 25 June 2020.

12. Thomas JL, Chaney DM, Dinucci KA, Eickmeier K, Rubin LG, Stapp MD, Vanore JV. Diagnosis and treatment of forefoot disorders. J Foot Ankle Surg. 2009;48:251-6.

13. Adams (II) WR. Morton's Neuroma. Clin Podiatr Med Surg. 2010;27:535-45.

14. Schreiber K, Khodaee M, Poddar S, Tweed EM, Inquiry EM. What is the best way to treat Morton's neuroma? Journal of Family Practitice. 2011;60:157-8.

15. Pace A, Scammell B, Dhar S. The outcome of Morton's neurectomy in the treatment of metatarsalgia. International Orthopaedices. 2010;34:511-5.

16. Volpe A, Tognon S, Fassina A. Morton's syndrome: surgical stratergies according to the digital nerve pathology. Foot Ankle Surg. 1998;4:129-37.

17. Redd RA, Peters VJ, Emery SF, Branch HM, Rifkin MD. Morton neuroma: sonographic evaluation. Radiology. 1989;171:415-7.

18. Zanetti M, Strehle JK, Zollinger H, Hodler J. Morton neuroma and fluid in the intermetatarsal bursa on MR images of 70 symptomatic volunteers. Radiology. 1997;203:516-20.

19. Flanagan G, Reilly I. Longitudinal plantar approach for excision of interdigital perineural fibroma of the foot: A case series and literature review. Foot and Ankle Online Journal, March 2016.

https://www.researchgate.net/publication/300005246_Longitudinal_plantar_approach_for_excision_of_interdigital_perineural_fibroma_of_the_foot_A_cas Accessed 25 June 2020.

20. Lee K, Kim J, Young K, Park Y, Kim J, Jegal H. Long-term results of neurectomy in the treatment of morton's neuroma: More than 10 years' follow-up. Foot Ankle Spec. 2011;4:349-53.

21. Womack JW, Richardson DR, Murphy GA, Richardson EG, Ishikawa SN. Long-term evaluation of interdigital neuroma treated by surgical excision. Foot Ankle Int. 2008;6:574-7.

22. Giannini S, Bacchini P, Ceccarelli F, Vannini F. Interdigital Neuroma: Clinical Examination and Histopathology Results in 63 Cases Treated with Excision. Foot Ankle Int. 2004;2:79-84.

23. Stamatis ED, Myerson MS. Treatment of recurrence of symptoms after excision of an interdigital neuroma. A retrospective review. Journal of Bone Joint Surgery. 2004;1:48-53.

24. Coughlin M, Pinsonneault T. Operative Treatment of Interdigital Neuroma. A long-term follow-up study. Journal of Bone Joint Surgery. 2001;9:1321-8.

25. Benedetti RS, Baxter DE, Davis PF. Clinical results of simultaneous adjacent interdigital neurectomy in the foot. Foot Ankle Int. 1996;5:264-8.

26. Wilson S, Kuwada GT. Retrospective study of the use of a plantar transverse incision versus a dorsal incision for excision of neuroma. J Foot Ankle Surg. 1995;35:537-40.

27. Schroven I, Geutjens G. Results of excision of the interdigital nerve in the treatment of Morton's metatarsalgia. The Foot. 1995;5:196-8.

28. Pinsker E, Daniels TR. AOFAS Position Statement Regarding the Future of the AOFAS Clinical Rating Systems. Foot Ankle Int. 2011;32:pp841-842.

29. Coutts A, Kilmartin TE. Dorsiflexory Phalangeal Osteotomy for Grade II Hallux Rigidus: Patient-Focused Outcomes at Elevan-Year Follow-Up. Journal of Foot Ankle Surgery. 2018;1:17-22.

30. Caporusso EF, Fallat LM, Savoy-Moore R. Cryogenic neuroblation for the treatment of lower extremity neuromas. Journal of Foot Ankle Surgery. 2018;5:286-90.

31. Saygi B, Yildirim Y, Saygi EK, Kara H, Esemenli T. Morton Neuroma: comparative results of two conservative methods. Foot Ankle Int. 2005;7:pp556-559.

32. Markovic M, Chrichton K, Read JW, Lam P, Slater HK. Effectiveness of ultrasound-guided corticosteroid injection in the treatment of Morton's neuroma. Foot Ankle Int. 2008;5:483-7.

33. Espinosa N, Seybold JD, Jankauskas L, Erschbamer M. Alcohol sclerosing therapy is not an effective treatment for interdigital neuroma. Foot Ankle Int. 2011;6:576-80.

34. Pasquali C, Vulcano E, Novario R, Varotto D, Montoli C, Volpe A. Ultrasound-guided alcohol injection for Morton's neuroma. Foot Ankle Int. 2015;1:55-9.

\section{Figures}




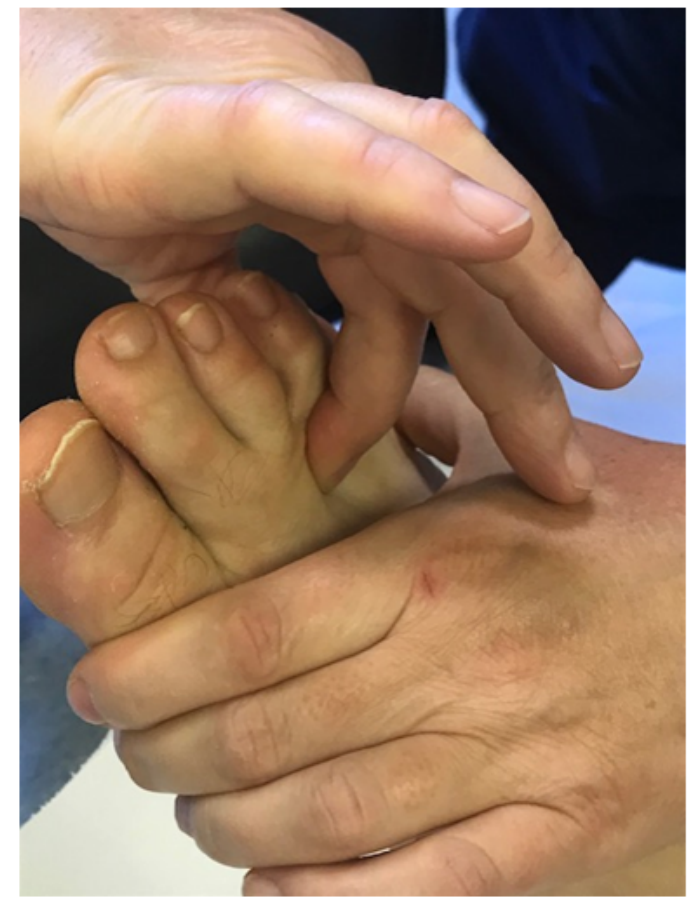

Figure 1

bilateral squeeze test

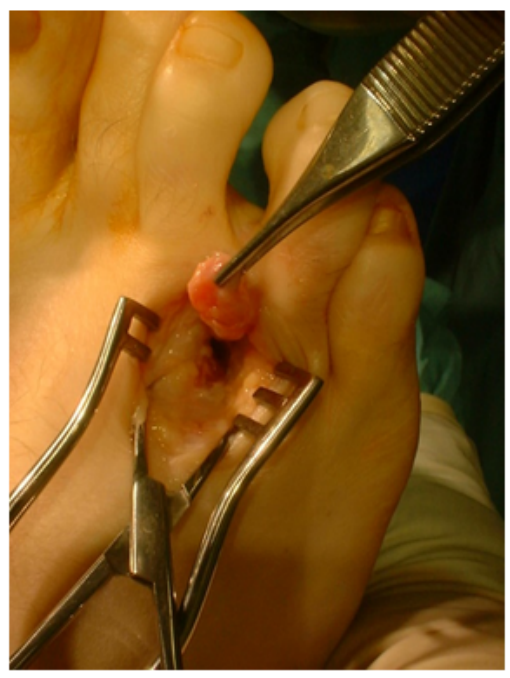

Figure 2

Neuroma identified intra-operatively 